if he ever sees, or has occasion to examine, a female patient of any age, from a week to 90 years.

At the end of the book are 17 plates of beautiful colour illustrations and an index which enhances the work's value as a book of reference.

There are, altogether, 26 chapters which range from the Psychosomatics of Gynaecology, which rightly has pride of place, to Pitfalls in Gynaecological Diagnosis, which reminds us of the mistakes we can all make.

The new chapter on Pediatric Gynaecology is especially valuable and the authors have been right to include a chapter on the diagnosis of breast conditions, for no gynaecological examination is really complete without examination of the breasts.

The only shame about this book is that no-one in England thought of doing it first!

E.E.P.

\section{ORTHOPAEDIC SURGERY IN INFANCY AND CHILDHOOD}

By Albert Barnett Ferguson Jn., B.A., M.D. Pp. xii +508 , with 504 illustrations. London: Baillière, Tindall \& Cox Ltd. 1957.

Although the title of Dr. Ferguson's book may make us wonder when we can expect a work on 'Paediatric Surgery in Children,' it is difficult to see what else he could have called a book dealing with the straightening of children. The exclusion of fractures has enabled Dr. Ferguson to produce a book which is short enough to be easily readable and long enough to present the subject with a reasonable amount of detail. The arrangement of the first six chapters on a regional basis has all the advantages of this method in ease of access to a particular problem and is on the whole successful. In the next three chapters, which deal successfully with affections of bone, and of muscle and with neurogenic affections, there is some inevitable repetition of what has gone before but this is never obtrusive. In the final chapter Dr. Ferguson deals concisely and well with malignant tumours of bone. Five other well-known men-four orthopaedic surgeons and one paediatrician-contribute sections on various aspects of the subject. These are valuable contributions which enhance the value of the book without producing any marked unevenness or introducing any contradictory teaching.

Dr. Ferguson's descriptions of clinical states are detailed and instructive and the methods of treatment advised are logically developed from consideration of the underlying pathology. The tendency in treatment is in general conservative and it is agreeable to find that in this respect much traditional dead wood has been cut away. English readers may be surprised to find relatively little space given to bone and joint tuberculosis and in particular to Pott's Paraplegia. More space could with advantage have been given to the treatment of the latter condition.

The illustrations are excellent and the references given are numerous and well chosen. The standard of production is generally high, though there are various small but tiresome misprints of English names. Potts is no longer in a position to object to this, but Dennis-Browne, Fairbanks and Seddorn may be a little vexed.

\section{SORANUS’ GYNECOLOGY}

Translated with an introduction by OwsEI TemkIN, M.D. Pp. xlix +258 . London: Geoffrey Cumberlege, Oxford University Press. 1955. $40 s$.

The translation of Soranus' Gynecology is obviously a labour of love.

It is most interesting to see how up-to-date some of the ideas of a gynaecologist who lived in the time of the emperors Trajan and Hadrian $(98-138)$ can be.

Soranus was a Greek who later went to Rome.

His book covered most of the symptoms which still present as gynaecological symptoms. Not all the treatments are hopelessly out of date.

For instance, the dilute acid treatment of a prolapsed uterus with ulceration, after replacing the uterus and packing the vagina with a tampon, is still good treatment.

There has clearly been great team work in producing this translation from the Greek, with plentiful reference to German literature bearing on the times.

E.E.P.

\section{ESSENTIALS OF MODERN SURGERY .}

Edited by R. M. HANDFIEld-JoneS, M.C., M.S., F.R.C.S. and Sir ARTHUR E. PORRITT, K.C.M.G., C.B.E., M.A., M.Ch., F.R.C.S. Fifth edition. Pp. xv + 1,276, with 649 illustrations, many in colour. Edinburgh: E. \& S. Livingstone Ltd. I957. $75 \mathrm{~s}$.

H. J. \& P., as this text book is so well known, reached its 19 th birthday this year and celebrated it with a fifth edition.

The book has been thoroughly revised and much new subject matter introduced without losing the essential character of the book. It is still a text book of surgery contained within one volume and has continued to lay emphasis on the fundamental principles of surgery. It is, therefore, a necessary part of the library of every undergraduate or graduate student of surgery.

The chief virtues of this book lie in the careful presentation of its subject matter which is well defined and classified as well as being well written. Each subject is given a solid pathological foundation from which diagnosis and treatment are deduced. Common disorders are dealt with at length and rarities but briefly mentioned. A notable exception is ulcerative colitis, an increasingly important disorder which is rather peremptorily dismissed. 